\title{
Aceno sobre Jovem e Existência
}

\section{Gustavo Fronza de Prá}

Resumo: O presente trabalho de estudo teórico busca retratar a situação atual do jovem, dos seus potenciais para se realizar e do porque geralmente não o faz. Existem barreiras que defletem o modo como o jovem enxerga o mundo fenomenizado através de modos comportamentais estabelecendo padrões que não são funcionais diante todos os momentos. O texto traz uma pequena abordagem dos estereótipos sociais que modelam o comportamento do jovem tornando-o rígido sem alcance da realidade e um breve aceno dos instrumentos de intervenção e da pedagogia ontopsicológica, soluções trazidas pela Ontopsicologia na finalidade de intervir visando um caráter mais funcional para o jovem e para a sociedade

Palavras-chave: Jovem; Estereótipo; Responsabilidade.

\section{Wave about Young and Existence}

Abstract: The present work of theorical study aims to show young's today situation, of their potentials to accomplish and the reasons why they usually don't do it. There are barriers that deflect the way the they see the phenomenical world through default behaviors that stablish patters that aren't functional in all the moments. The work brings a small approach of the social stereotypes that sculpt the young's behavior, making him rigid, without being able to reach reality, and a brief wave of the instruments of intervention and the ontopsychological pedagogy, solutions brought by Ontopsychology in the objective of intervene aiming a more functional character to the young and for the society.

Keywords: Young; Stereotype; Responsibility.

\section{Exposición sobre joven y existencia}

Resumen: El presente trabajo de estudio teórico busca retratar la situación actual del joven, de sus potencialidades para la realización personal y del porqué, generalmente, el joven no lo hace. Hay barreras que apartan el modo como el joven ve el mundo a través de modos comportamentales establecidos en patrones que no son funcionales ante todos los momentos. El texto trae un pequeño abordaje de los estereotipos sociales que modelan el comportamiento del joven, haciéndolo rígido sin alcance de la realidad y una breve exposición de los instrumentos de intervención y de la pedagogía ontopsicológica, soluciones traídas por la Ontopsicología con la finalidad de intervenir, visando una formación de carácter más funcional para el joven y para la sociedad.

Palabras clave: Joven; Estereotip; Responsabilidad. 


\section{Introdução}

A presente pesquisa visa retratar de modo teórico a situação que aflige a maioria das pessoas quando, no período da juventude, surge a procura pela verdade fundamental da própria vida. Esta abordagem se dá a partir da ótica ontopsicológica.

O jovem é detentor de uma enorme potencialidade ${ }^{1}$ e virtualidade ${ }^{2}$ que precisam ser conhecidas e colocadas em prática para que realize uma história de valor. Porém, para que isso ocorra o jovem necessita estar em contato com o seu projeto real e único o qual a natureza lhe forneceu, mas que, porém, a vida em sociedade modificou a partir de suas estruturas. O problema se caracteriza a partir do momento em que os estereótipos desenvolvidos dentro da cultura social formam a lógica e por consequência, o comportamento da criança, futuramente repetido pelo indivíduo adulto.

O ser humano se desenvolve partindo da lógica aprendida no externo e não pela tensão constante que está dentro si mesmo. Com isso, a evolução que se faz não é igual com o projeto que deveria ser feito, não segundo a própria identidade.

O Acadêmico Professor Antonio Meneghetti entende que o ser humano deve "formalizar uma consciência em uníssono com a identidade de natureza: tornar-se pessoa em conformidade com o projeto da vida, andar junto com o princípio que nos substancia" (MENEGHETTI, 2013, p. 25). Ainda mais:

O primeiro ponto é a metanoia. Descobrir a si mesmo em base à identidade ôntica, ou seja, saber-se como é e não como pensa. É preciso chegar com a boa vontade, a humildade e a Ontopsicologia pode auxiliar porque é um método radical, técnico, lógico, que faz ver rapidamente se você é ou não é, se é você ou um outro (MENEGHETTI, 2014, p. 86).

Portanto, se o jovem está defasado, está fora do seu verdadeiro, deve fazer a metanoia ${ }^{3}$. O processo é realizado através da Consultoria de Autenticação, e reorganiza o

\footnotetext{
1 "Potência ao ato. Possibilidade prevista no habitat ou organograma geral do ambiente ecológico ou do indivíduo distinto" (MENEGHETTI, A. Dicionário de Ontopsicologia. Recanto Maestro: Ontopsicológica Editora Universitária, 2012, p. 212).

${ }^{2}$ De acordo com Meneghetti: "Forma específica que se pode extrair ou realizar de um contexto ou coisa" (ibid, p. 270).

${ }^{3}$ Mudança radical de mente. Mais informaçõesem: MENEGHETTI, A. Dicionário de Ontopsicologia. Recanto Maestro: Ontopsicológica Editora Universitária: 2012, p.172.
} 
modo comportamental do ser humano, o deixando de acordo com a intencionalidade ${ }^{4}$ do seu Em Si ôntico 5 .

Depois que se atinge uma determinada maturidade, quando o indivíduo já consegue ter um autoconhecimento, já mudou, é necessário que ele tenha dentro do seu projeto de natureza um sentido maior, um valor que o mantenha autêntico defronte as diversas dificuldades que normalmente aparecerão.

\begin{abstract}
Ao declarar que o ser humano é uma criatura responsável e precisa realizar o sentido potencial de sua vida, quero salientar que o verdadeiro sentido da vida deve ser descoberto no mundo, e não dentro da pessoa humana ou de sua psique, como se fosse um sistema fechado (FRANKL, 2013, p. 135).
\end{abstract}

O sentido que ele deve dar é extremamente correlacionado com o seu projeto de natureza. Sabendo o seu projeto, como foi constituído e como realmente é, ele deve dar um sentido maior, por exemplo: o jovem que possuía uma intencionalidade para ensinar descobriu que gosta de passar seus conhecimentos a outras pessoas, mas principalmente de ver estas pessoas aplicarem os conhecimentos em suas vidas e terem uma evolução, uma significativa melhora em todos os aspectos. Então, decide que será professor para poder realizar seu objetivo que é na realidade auxiliar na transformação de outras pessoas. Assim, ele direciona sua vida para fazer isso, primeiro deve estudar, se formar, mas sempre visando o sentido maior que tem sua vida.

Quando isto não ocorre o sujeito acaba ficando "robotizado", pois ele sabe que deveria realizar algo, mas não sabe o que é e muito menos como deveria começar. Faz aquilo que os outros mandam, o que a sociedade imposta a ele, nesse caso, o projeto de natureza não é algo que lhe faz sentido. Contudo, as pessoas tendem a serem frustradas, pois certamente estão no caminho errado e não conseguem realizar o pleno de si mesmas descontando suas energias de forma não funcional na sociedade, que ao contrário do que deveria fazer, sempre os acaba patologicamente os acolhendo, tirando-lhes a responsabilidade e os deixando no comodismo existencial.

É importante salientar que o presente trabalho foi realizado por meio da metodologia de estudo teórico e contém sua importância por dar evidência ao modo como os indivíduos são formados com base nos estereótipos. Destaca-se a proposta de solução

\footnotetext{
4 "Estrutura formal que vincula a modalidade da ação. A direção na qual a ação se homologa e se configura de per si no interior de um contexto" (MENEGHETTI, A. Dicionário de Ontopsicologia. op. cit. p. 140). 5 "Princípio ôntico existencial do homem" (MENEGHETTI, A. Dicionário de Ontopsicologia. Op. Cit., p. 84).
} 
que a ciência Ontopsicológica traz para que o indivíduo reencontre o próprio projeto de natureza e assim possa se realizar. Dentro disto, é possível que a partir da solução indicada os indivíduos sadios consigam desenvolver uma sociedade mais funcional.

\section{Fundamentação teórica}

\subsection{Quem é o jovem?}

O Acadêmico Prof. Antonio Meneghetti (2005) define o jovem como aquele que tem no íntegro o potencial de poder dar evolução biológica, funcional, estética, de liderança como top líder. Não pode ser circunscrito em uma identidade precisa. "Íntegro" significa que neste indivíduo existe uma relação ainda ativa entre Em Si ôntico e Eu lógico-histórico ${ }^{6}$.

É um ser que possui um potencial natural, sendo que para o jovem as coisas se tornam mais fáceis, eles aprendem mais rápido, sem contar com a enorme energia de ação que está sempre vibrando em suas almas. Mas este potencial deve ser descoberto e após, deve ser incessantemente realizado o investimento para o desenvolvimento e concretização do mesmo. É assim necessária uma atenção de total intencionalidade sobre o caminho em que é próprio seu, em que é mais apto seguir para, a partir disso, iniciar sua trajetória de realização pessoal.

Embora aparentemente pareça ser fácil este processo, pois teoricamente somente seria necessário a descoberta do próprio potencial. No entanto, existe aspectos que fazem o indivíduo perder-se nesta trajetória. Existem os complexos, estereótipos, a vida em sociedade escolhida e que faz a mudança do modo natural de comportamento do sujeito.

\subsection{Quais são os principais desvios?}

Os maiores estereótipos, segundo Meneghetti (2013), que cortam a possibilidade de autoconstrução entre os jovens principalmente na idade de 14 a 24 são o biologismo, o idealismo crítico e o consumismo.

\footnotetext{
${ }^{6}$ A parte lógica e consciente de todas as operações voluntárias, responsáveis, reflexivas, inteligentes, racionais, mnemônicas etc. (MENEGHETTI, A. Dicionário de Ontopsicologia. Op. cit., p. 270).
} 
O biologismo pode ser como corpo, familístico e ter a relação com o líder. Entendese uma certa exaltação do próprio corpo com tudo que está em conectividade a ele, a priorização pelo ciclo biológico e também há a transcendência deste estereótipo, mantendo um certo relativismo. No entanto, é uma desresponsabilização por parte dos jovens, que preferem ficar escondidos atrás do estereótipo a encarar a vida como é. Entretanto, "se os jovens conhecem as consequências daquilo que põem como premissa de um biologismo standart, já estão preparados para jogar bem” (MENEGHETTI, 2013, p. 53).

O idealismo crítico, segundo Meneghetti (2013) é um preciso comportamento de alguns jovens que, por já possuírem determinada capacidade de compreensão de mundo acreditam estar prontos para a vida. Eles sentem já ter chegado a um patamar superior, até mesmo maior que dos adultos e acabam acomodando-se sem ter o crescimento que poderiam ter. A questão é que ao identificarem os vários defeitos e imperfeições que os adultos possuem, eles não são mais aqueles perfeitos, os quais imaginavam quando crianças. Assim sendo, o jovem não se prepara para as circunstâncias da vida a cada dia, é claro que terá muito sacrifício, contudo, a vivência destes é necessária para fazer realizarse o potencial que se tem. "Mas o tempo da glória chegará somente se o jovem coloca as premissas, investindo bem no hoje e em cada dia futuro: o sucesso quer o investimento máximo de si mesmo.” (MENEGHETTI, 2013, p. 64).

Por último vem o consumismo, algo extremamente comum para com os jovens da atualidade, influenciados a estarem consumindo algo pela mídia e, os meios de comunicação sabendo deste mercado, os forçam para que produtos oferecidos sejam de fácil apego e desejo. Os mais prejudicados nisso são os jovens que acreditam estarem consumindo, mas na verdade, são eles consumidos por este frenético circuito em que o estereótipo sustenta a economia mundial. Na realidade, os jovens são cobaias e futuras vítimas para que os "grandes" que controlam o mundo possam identificar tendências que irão impor futuramente novos estereótipos à grande massa.

Ainda mais, há a juventude viciada em álcool, drogas e sexo. É difundido entre os próprios jovens que para serem aceitos em determinados grupos sociais eles devem se adequar com o vício mais frequente naquele grupo. Por exemplo, se o jovem que não bebe frequentemente começa a sair todo final de semana com um grupo que teve como principal objetivo contar "quantas garrafas de álcool restaram vazias no noite", ele inicia o mesmo, buscando ser aceito pelo grupo. O jovem quer "fazer parte de algo", estar junto de outras 
pessoas. Por fim, acaba dependente de coisas do externo, não possuindo autonomia nenhuma para viver.

Outro fato é o jovem internetiano. Já nasceu conectado à grande rede, principalmente porque os pais permitem o contato em tempo integral com as redes, com a televisão, então, são replicadores de estereótipo vivendo num mundo imaginário. Assim surge a dificuldade em lidar com o mundo real, isto porque nunca viveram de fato nele, nunca o experimentaram. Meneghetti ressalta a relação entre o uso da internet e a vivência dos estereótipos:

\footnotetext{
"A Ontopsicologia descobriu a presença do monitor de deflexão, por isso, a internet é a natural web do m.d.d ${ }^{7}$, que não serve nem respeita a realidade: a internet faz ao seu modo, não está conexa com o real, mas sim com o imaginário sem base natural" (MENEGHETTI, 2014, p. 23).
}

A partir da vivência desses comportamentos baseados no monitor de deflexão ${ }^{8} \mathrm{o}$ jovem acaba destruindo as possibilidades de realizar o pleno de si mesmo e fica apenas contribuindo para termos uma juventude mais doente e mais restrita ao que é o standard da massa.

\subsection{Como o jovem pode resgatar sua identidade?}

Os instrumentos de intervenção da Ontopsicológia com base em uma pedagogia com os jovens pautada na realização de si mesmos pode ser o caminho para uma transformação. A Pedagogia Ontopsicológica traz a ótica da responsabilidade, onde o indivíduo deve responder em primeira pessoa pela sua vida, não terceirizando o encargo aos outros, à sociedade, à família etc. Com isto, é possível mudar cada indivíduo, torná-los mais autônomos e sadios, mais engajados em fazer o melhor de si mesmos. Em consequência teremos uma sociedade também mais sadia e funcional para o homem.

Através da Consultoria de Autenticação ${ }^{9}$ é realizada a metanoia. Então, o indivíduo que é criado dentro de uma determinada cultura, de uma determinada sociedade, de um determinado modo, agrega informações que não são na sua realidade idênticas a quem ele é em sentido ôntico, não são realmente suas. A pessoa absorve estas informações e ali

\footnotetext{
${ }^{7}$ A abreviação refere-se ao termo "monitor de deflexão" m.d.d.

8 "Engenho psicodélico deformador das projeções do real à imagem” (MENEGHETTI, A. Dicionário de Ontopsicologia. Op. cit., p. 175).

9 Relação dialógica entre o especialista técnico em Ontopsicologia e um cliente em busca de uma solução pessoa, política, econômica. (MENEGHETTI, A. Dicionário de Ontopsicologia. Op. cit., p. 65).
} 
permanece formando um novo jeito de viver, com escolhas que não são funcionais para a sua realização pessoal. Com isso, torna-se necessário que aconteça um processo de mudança de comportamento, que tem início, em seu processo, pelo modo como a pessoa pensa e consequentemente age em cada situação. Não é um processo fácil e rápido, mas será valioso porque ao final a pessoa será verdadeira para si e para a sociedade.

Outra abordagem ontopsicológica é o método denominado Cinelogia ${ }^{10}$, conduzido por um técnico especializado, acontece quando a pessoa assiste a um filme e consegue perceber aspectos próprios porque em determinadas cenas chorou, sorriu, ficou feliz etc. Isto acontece porque viveu aquelas emoções. Então, quando na vida real acontece algo parecido ela provavelmente terá a mesma emoção que teve assistindo ao filme. A Cinelogia proporciona ao indivíduo analisar seus modos de comportamento em algumas situações e assim conscientiza-lo e corrigi-los se for o caso.

Há também a Melolística ${ }^{11}$, a atividade trabalha o corpo dos participantes com a música. Ajuda a pessoa a readquirir o contato com o cérebro viscerotônico ${ }^{12}$, possibilitando uma melhor percepção própria de sua construção.

O Residence Ontopsicológico ${ }^{13}$ é o instrumento mais integral, pois envolve, dependendo do modelo a ser feito, vários dos outros instrumentos numa mesma experiência de tempo, o sendo realizado durante alguns dias. Ainda mais:

Fazer um Residence segundo a metodologia ontopsicológica substancialmente significa fazer uma verificação se o próprio estado de ser e a própria produção de vida é ou não é funcional ao crescimento, ao bem-estar e à satisfação de toda a unidade de ação que se é (MENEGHETTI, 2005, p. 21).

Desse modo, por meio dos vários instrumentos que a Ontopsicologia apresenta, o jovem, de forma natural, vai compreendendo e modificando aquilo que está fora do caminho em seu projeto de natureza.

\section{Metodologia}

\footnotetext{
${ }^{10}$ Para maiores informações: MENEGHETTI, A. Manual de Ontopsicologia. Recanto Maestro: Ontopsicológica Editrice, 2004, p. 377.

${ }^{11}$ Ibid, p. 397.

${ }^{12}$ Complexo de ações e reações determinadas por sinapses neurônicas alojadas no aparato intestinal. (MENEGHETTI, A. Dicionário de Ontopsicologia. Op. cit., p. 84).

${ }^{13}$ Para maiores informações: MENEGHETTI, A. Manual de Ontopsicologia. Recanto Maestro: Ontopsicológica Editrice, 2004, p. 387.
} 
A presente pesquisa foi realizada a partir do estudo bibliográfico, portanto teórico, fundamentado em revistas, livros, documentos, palestras, áudios e vídeos. Deu-se, assim, um breve aceno sobre quem é o jovem, suas principais dificuldades e possibilidades, assim como acerca da solução destas por meio da Ontopsicologia enquanto ciência. Por fim, espera-se que a partir desta pesquisa produzam-se novos trabalhos mais aprofundados sobre os temas aqui abordados, bem como, novas hipóteses e caminhos de soluções para as problemáticas existenciais.

\section{Resultados e Discussão}

Diante da evidente crise entre os jovens é inevitável que a indagação sobre a educação surja. Como está a educação hoje? Seria ela também uma causadora da crise juvenil?

É possível perceber pelos resultados visualizados, que o modelo de pedagogia utilizado hoje não é funcional para o jovem e para a sociedade. A formação desenvolve alunos sem o pensamento crítico que deveriam ter diante de tantas coisas, onde eles deveriam assumir a responsabilidade de identificar adequadamente se estão certas ou erradas.

O jovem vai à escola mais por obrigação dos pais, pelo sistema controlador, inserido num ciclo estereotipado bastante extenso, por exemplo: um professor de escola pública passa sua aula para cumprir o horário e ganhar seu salário ao final do mês, não se esforça para tentar recuperar aquele jovem que tem dificuldade de aprender porque já vem de um ambiente familiar hostil aos estudos. A família desse jovem possui pouco conhecimento e cultura para incentivar o jovem a buscar algo mais em sua vida, necessitando, antes de tudo, garantir sua pequena subsistência através do trabalho. No que se refere ao estado, o sistema tem medo de revoluções. É um ciclo sem fim, as pessoas não são formadas para serem cidadãos responsáveis capazes de fazer evolução de si e do meio social, são apenas números dentro da sociedade caótica que existe no momento.

Com isto surge um novo conceito para formar o ser humano, no qual o coloca como centro das ações da vida, a responsabilidade dada pela Pedagogia Ontopsicológica, esta é entendida como "a arte de formar o homem-pessoa na função social" (MENEGHETTI, 2012, p. 207). A Pedagogia ontopsicológica repropõe o modelo de formação das pessoas na educação, dando a elas a real responsabilidade que possuem 
como indivíduos dentro do meio social. Elas são capazes, tem energia e inteligência, mas falta a própria responsabilização de atuar, respondendo em primeira pessoa pela sua vida.

A Pedagogia Ontopsicológica utiliza um critério: o Em Si ôntico. Todos possuem um potencial que vem do Em Si ôntico, indicando uma tendência para determinada área de atuação, para um determinado saber fazer, apontando uma vocação. A Ontopsicologia, através da sua pedagogia, busca que cada indivíduo possa saber qual é esta sua identidade de projeto e a desenvolva plenamente para se realizar e também poder realizar história para a sociedade. É um direito de cada pessoa receber uma educação que seja funcional para si e também um dever dela partindo desta educação ser uma pessoa que saiba aproveitá-la e retribuí-la à sociedade.

A partir de sua bibliografia, entende-se que o período da juventude é um dos mais dramáticos na vida do ser humano, isto porque ele começa a entender-se como pessoa existente no mundo, como milhares de informações sobre diferentes caminhos a seguir. Ainda mais, há a experiência de vazio existencial, no qual faltaria algo fundamental para poder ter uma trajetória conforme seu projeto de natureza no mundo real da vida.

\section{Considerações Finais}

Por meio da presente pesquisa foi possível compreender que a juventude mesmo com todo o potencial que possui não realiza-se em identidade ôntica. A maioria esconde-se por trás de estereótipos sociais que então comandam suas vidas. Destacamos e pudemos notar, sobretudo, o: biologismo, idealismo crítico e o consumismo.

No entanto, a Pedagogia desenvolvida por meio dos métodos da ontopsicologia são caminho para a afirmação d identidade, favorecendo a formação de pessoas capazes de construírem uma existência autêntica a partir do Em Si ôntico.

Por fim, o trabalho contribui para que mais jovens e adultos saibam daquilo que dispomos em nossa estrutura, uma enorme capacidade e inteligência a favor do ser do fazer.

\section{Referências}

CAROTENUTO M. A paideia ôntica. Dos Sumérios a Meneghetti. Recanto Maestro: Ontopsicológica Editora Universitária, 2013. 
FRANKL V. Em busca de sentido. 25. ed. Rio de Janeiro: Editora Vozes, 2012.

MENEGHETTI, A. A arte de viver dos sábios. 3. ed. Recanto Maestro: Ontopsicológica Editora Universitária, 2009.

MENEGHETTI, A. Dicionário de Ontopsicologia. 2 ed. Recanto Maestro: Ontopsicológica Editora Universitária, 2012.

MENEGHETTI, A. Do humanismo histórico ao humanismo perene. Recanto Maestro: Ontopsicológica Editora Universitária, 2014.

MENEGHETTI, A. Manual de Ontopsicologia. Recanto Maestro: Ontopsicológica Editrice, 2004.

MENEGHETTI, A. Nova Fronda Virescit: introdução à Ontopsicologia para jovens. Recanto Maestro: Ontopsicológica Editora Universitária, 2014.

MENEGHETTI, A. Nova Fronda Virescit: Introdução à psicoterapia ontopsiológica, instrumentos e aplicações. Recanto Maestro: Ontopsicológica Editora Universitária, 2014.

MENEGHETTI, A. Nova Fronda Virescit: em busca da alma. Recanto Maestro: Ontopsicológica Editora Universitária, 2010.

MENEGHETTI, A. Os jovens e a ética ôntica. Recanto Maestro: Ontopsicológica Editora Universitária, 2013.

MENEGHETTI, A. Pedagogia Ontopsicológica. 3 ed. Recanto Maestro: Ontopsicológica Editora Universitária, 2010.

MENEGHETTI, A. Residence Ontopsicológico. 3 ed. Recanto Maestro: Ontopsicológica Editora Universitária, 2005.

SCHAEFER, R. (Orgs.) Identidade Jovem: a formação humanista de jovens como garantia de sustentabilidade, identidade e protagonismo civil. Recanto Maestro: Associação Brasileira de Ontopsicologia, 2011. 